\title{
The gravity of foreign news coverage in the EU: does the euro matter?
}

\author{
Andrea Fracasso \\ Department of Economics and Management \&s School of International Studies, \\ University of Trento \\ Nicola Grassano \\ SPRU - Science and Technology Policy Research, University of Sussex; \\ Knowledge for Growth Unit, Institute for Prospective Technological Studies (IPTS) \\ Giuseppe Vittucci Marzetti* \\ Department of Sociology ad Social Research, University of Milano-Bicocca
}

\begin{abstract}
This work investigates the systemic factors behind cross-country variability in the transnational media coverage of foreign news in the EU in 2010. Using a large dataset on the transnational coverage of news by $148 \mathrm{EU}$ national media, the paper maps the network of EU transnational citations and performs a quantitative assessment of their systemic determinants via the estimation of a gravity model of news. Nine empirical hypotheses are tested. Size and economic development of the target (source) country are positively (negatively) associated with the probability of coverage. Historical, linguistic and economic ties increase this probability. The evidence on the effect of the countries' participation in the currency union is weak: once the historical levels of trade integration and the effects of the sovereign debt crisis are accounted for, there is no robust evidence of a higher integration of the media spheres within the euro area.
\end{abstract}

Key words: Complex networks, European Union, Eurozone, Gravity model, Media sphere.

JEL Classification: C210, F330, F500, F690, Z100

\footnotetext{
${ }^{*}$ Corresponding author: Department of Sociology ad Social Research, University of MilanoBicocca, via Bicocca degli Arcimboldi 8, 20126 Milan, Italy Phone: +39 0264487457, Fax: +390264487561

Email addresses: andrea.fracasso@unitn.it (Andrea Fracasso), n.grassano@sussex.ac.uk (Nicola Grassano), giuseppe.vittucci@unimib.it (Giuseppe Vittucci Marzetti)
}

Preprint submitted to JCMS: Journal of Common Market Studies 


\section{Introduction}

The establishment of the Economic and Monetary Union is the most advanced form of economic integration observed so far in the European Union (EU). It has brought about a wide range of far-reaching changes in member countries, both at the macroeconomic and microeconomic levels, as shown by the vast literature aimed at assessing the impact of the common currency on the Euro Zone (EZ) (e.g. Rose, 2000; Sander and Kleimeier, 2004; Baldwin and Taglioni, 2007; Bonatti and Fracasso, 2013).

Likely, the adoption of the euro has also affected public debates, pushed further the transformation of the national public spheres, and modified the orientation of foreign news coverage. Sharing the same currency area raises the likelihood and the size of cross-border economic and political spillovers, increases the interdependence among countries, and fosters the importance of common actions (or lack thereof). Even short of creating a community of fate, EZ countries become more interdependent because of the very fact of sharing the same currency, central bank, exchange rates, and the like. Thus, events in EZ member states acquire greater salience for the remaining EZ members. In fact, when the euro was established, this strengthening of the economic integration was generally viewed, in particular by the European federalists, as a way to foster political and social integration, including the Europeanization of the national media spheres. ${ }^{1}$

Although plausible, the hypothesis that the European news coverage has been affected by the EZ membership has not been empirically tested yet. While the literature has already addressed how the national media presented (and added to) the debate on the euro (e.g. Werder, 2002; Brettschneider et al., 2003), there exists a gap concerning whether and how journalism responded to the modification of the political and institutional environment following the process of monetary integration. In other words, if and to what extent there is a euro-related dimension of journalism and media communication.

Taking stock of previous quantitative works on the determinants of foreign news, we analyse the "systemic determinants" (Wu, 2000) of the international news coverage in the European press and, in particular, the impact of the EZ membership on transnational coverage. The systemic factors under investigation (both national traits and measures of relatedness, such as population, economic development, physical distance, trade, common language and historical linkages) are those identified in previous quantitative studies (see, among the others, Wu, 2000; Brüggemann and Kleinen-von Königslöw, 2009); to this set of factors we add the main variable of interest, i.e. EZ membership, and a few dichotomous variables to capture crisis-related sources of newsworthiness in the period under investigation (in line with Galtung and Ruge, 1965). ${ }^{2}$ Of the alternative forms

\footnotetext{
${ }^{1}$ Greater foreign news coverage within the EZ could also facilitate the achievement of what economists call an "optimum currency area" (see, for instance, Frankel and Rose, 1998).

${ }^{2}$ We do not address all the possible individual and societal determinants of foreign news value, the factors affecting the organization and the mission of each of the journals in the sample
} 
of Europeanization of public communication discussed in Koopmans and Erbe (2004) and Sifft et al. (2007), this work addresses neither European-wide mass media (often associated with the idea of a supranational public sphere, as in Firmstone, 2008a) nor the coverage of EU-related news by national media (known as vertical Europeanization) (e.g. De Vreese, 2001). Rather, following the distinction between horizontal and vertical Europeanization put forward by Koopmans and Erbe (2004), the analysis focuses on horizontal Europeanization, that is on the communicative linkages among the EU member states. For this reason, to describe and to analyse the news-related cross-country linkages we adopt complex empirical approaches able to account for bilateral relationships, respectively network analysis and a gravity model of news, recalling the gravity model of trade (e.g. Head and Mayer, 2014). The latter is an empirical framework that relates bilateral trade flows between any pair of countries to country-specific factors - such as the "economic mass" of the trading countries, measured in terms of their GDP - and pair-specific variables - such as the geographical distance. Instead of assessing the determinants of bilateral trade flows, in this work we investigate the determinants of bilateral cross-country coverage of foreign news. The candidate country- and pair-specific determinants we test will be chosen by following both previous studies and intuition.

This paper exploits a unique dataset on the transnational coverage of stories related to other EU member states by $148 \mathrm{EU}$ national newspapers. The paper contributes to the debate on European economic and media integration in two ways. First, given the number of news media and articles considered, it presents a comprehensive transnational coverage network in the EU, and draws a quantitative assessment on the systemic factors affecting the horizontal Europeanization of the European media sphere. Second, with respect to previous longitudinal newspaper studies, it adopts up-to-date empirical methods able to capture the common traits of the observed bilateral news-related linkages in the EU, thereby explaining the cross-country variability in the ways in which EU countries cover news regarding other EU countries. Third, by means of robust estimation methods, this work tackles whether journalists and editors working in EZ countries show relatively greater interest in what happens in their EZ partners than in what occurs in other EU members.

The remainder of the paper proceeds as follows. In Section 2, we present the data on the transnational coverage of national media in EU member states. In Section 3, we draw on and analyse the weighted directed network of citation probabilities in the national media for EU member states. In Section 4, we identify nine systemic factors that might exert influence on international news coverage and derive nine hypotheses to test; then, we present the gravity model of news adopted to assess the factors behind the observed structure of citation

(as done in smaller scale studies, such as Firmstone, 2008b; Brüggemann and Kleinen-von Königslöw, 2009, 2013), the barriers to effective coverage of foreign news (such as the logistic factors analysed in $\mathrm{Wu}, 2000$ ), and the journalists' personal responses to the emergence of a EZ dimension (as done in interview-based studies like Statham, 2008; Firmstone, 2008b). 
probabilities. Section 5 presents the main empirical findings. Section 6 concludes.

\section{Data}

To evaluate quantitatively the extent to which EU member states are covered by the media of other EU partners, it is first necessary to draw a homogeneous sample of news articles published in the EU. This work follows that done by Economisti Associati (2011) and covers all the articles (1.96 million) published between 16 August and 15 November 2010 by the major general and business newspapers in the EU countries and collected by the database Meltwater News (http://www.meltwater.com/products/meltwater-news/). ${ }^{3}$

Following Brüggemann and Kleinen-von Königslöw (2009), we focus mainly on the most influential daily national newspapers in each country, although the sample includes also a number of very influential regional newspapers (e.g. La Vanguardia and La Voz de Galicia in Spain) and weekly magazines (e.g. Le Nouvel Observateur in France, Der Spiegel in Germany, and The Economist in the UK). ${ }^{4}$ Compared to Brüggemann and Kleinen-von Königslöw (2009), our dataset has the advantage of covering all the EU countries, while it has the disadvantage of a limited time span, though this is not a reason for concern given the "horizontal" focus of our research.

As in Brüggemann and Kleinen-von Königslöw (2013), we measure foreign news coverage in terms of the presence of references to foreign EU countries in articles published in EU national media. References to foreign EU countries are sought in the title and body of every article through search strings containing the name of the target countries (translated into various languages) (see Economisti Associati, 2011, for details). This does not allow to look at the quality of coverage and to distinguish editorials from regular articles, events and political quotes, and the like. ${ }^{5}$ Although we reckon that looking at the content and specific sources of the coverage would provide further useful insights, we focus here on the extent of cross-country media coverage.

Once aggregated by nationality of origin, the total number of articles referring to each target country is divided by the total number of articles published in the

\footnotetext{
${ }^{3}$ The dataset was developed and released by Economisti Associati in the framework of a feasibility study for the preparatory action "Erasmus for journalists" commissioned by the DG Information Society of the European Commission, and implemented by a consortium led by The Evaluation Partnership and involving the European Journalism Centre. The research team responsible for the statistical review was led by Tommaso Grassi. The final report is available on the European Commission website: http://ec.europa.eu/information_society/ media_taskforce/doc/mobility/erjo_part2_report.pdf.

${ }^{4}$ The sources are generalist or business newspapers. Sport newspapers and infotainment tabloids are not included. The full list of newspapers can be found in Annex D of Economisti Associati (2011). The selection criteria are described in details in Annex C of the same report.

${ }^{5}$ For instance, we cannot distinguish journalists' references to EU partners from politicians' declarations about foreign countries, as done in Statham and Koopmans (2009). The citations are not weighted for the journals' copies, readers or market shares. Since we do not assess the impact of journal's foreign coverage on the domestic public opinion, this normalization is not necessary.
} 
source country; this will normalize the measure for the country-specific number of outlets and articles per outlet. Given any ordered pair of countries $(i, j)$, the unit of analysis, $p_{i j}$, is therefore the fraction of articles in the source country $i$ referring to the destination country $j$ among all the articles published in $i$; this can be conceived as the probability that an article published in $i$ refers to $j$. These figures are employed directly in the creation of the weighted directed network of transnational media coverage illustrated in Section 3.

In the empirical estimates (Sections 4 and 5), we use instead the logistic transformation of $p_{i j}, \operatorname{logit}\left(p_{i j}\right)=\log \left(\frac{p_{i j}}{1-p_{i j}}\right)$, i.e. the $\log$ of the odds in favour of picking an article referring to $j$ randomly choosing among all the articles published in $i$. In the various specifications to test the determinants of the transnational media coverage in the EU, we make use of both continuous and dichotomous variables, chosen in accordance with previous findings in the literature and with the hypotheses to test. The continuous variables include: the average population of the (source and target) countries over the period 2001-2010, from Eurostat; the average 2001-2010 GDP per capita in PPP, from Eurostat; the bilateral weighted distances, from CEPII; the bilateral trade flows as a fraction of the total international trade flows of the source country averaged over 1999-2000, from Eurostat; the average long-term interest rates over the period August-November 2010, from the ECB; the political orientation of the countries, from the 2010 Chapel Hill expert survey (CHES) (Bakker et al., 2012).

\section{The transnational coverage network in the EU}

The most direct and self-illustrative approach to analyse the transnational media coverage in the $\mathrm{EU}$ is to represent the citation probabilities $p_{i j}$ between the 27 countries as a weighted directed network (see, among the others, Barthélemy et al., 2005; Boccaletti et al., 2006). The nodes (or vertices) of the network are the $27 \mathrm{EU}$ member states, each link (or arc) $(i, j)$ represents the citations of $j$ made by articles published in $i$ with a weight given by $p_{i j}$.

The resulting network is plotted in Figure 1. In the graph, link thickness and darkness are proportional to the weights $\left(p_{i j}\right)$. The node size is proportional to the average in-weight, i.e. the average of the weights attached to incoming links, a measure of the importance of the country as a target. Node position is determined by two main forces: nodes were initially plotted according to the geographical position of the correspondent country, as determined by the capital city coordinates, and then moved by an algorithm that brings the nodes that are particularly strongly connected closer together. ${ }^{6}$

An inspection of the network reveals that it is characterized by heterogeneous relationships (for some descriptive statistics and a more formal exploratory analysis see the Appendix). Four dimensions of heterogeneity can be appreciated.

\footnotetext{
${ }^{6}$ The plot is made using Pajek 3.09 and applying the Kamada-Kawai algorithm. See De Nooy et al. (2011) for details on Pajek and further references on force-directed algorithms for drawing graphs.
} 

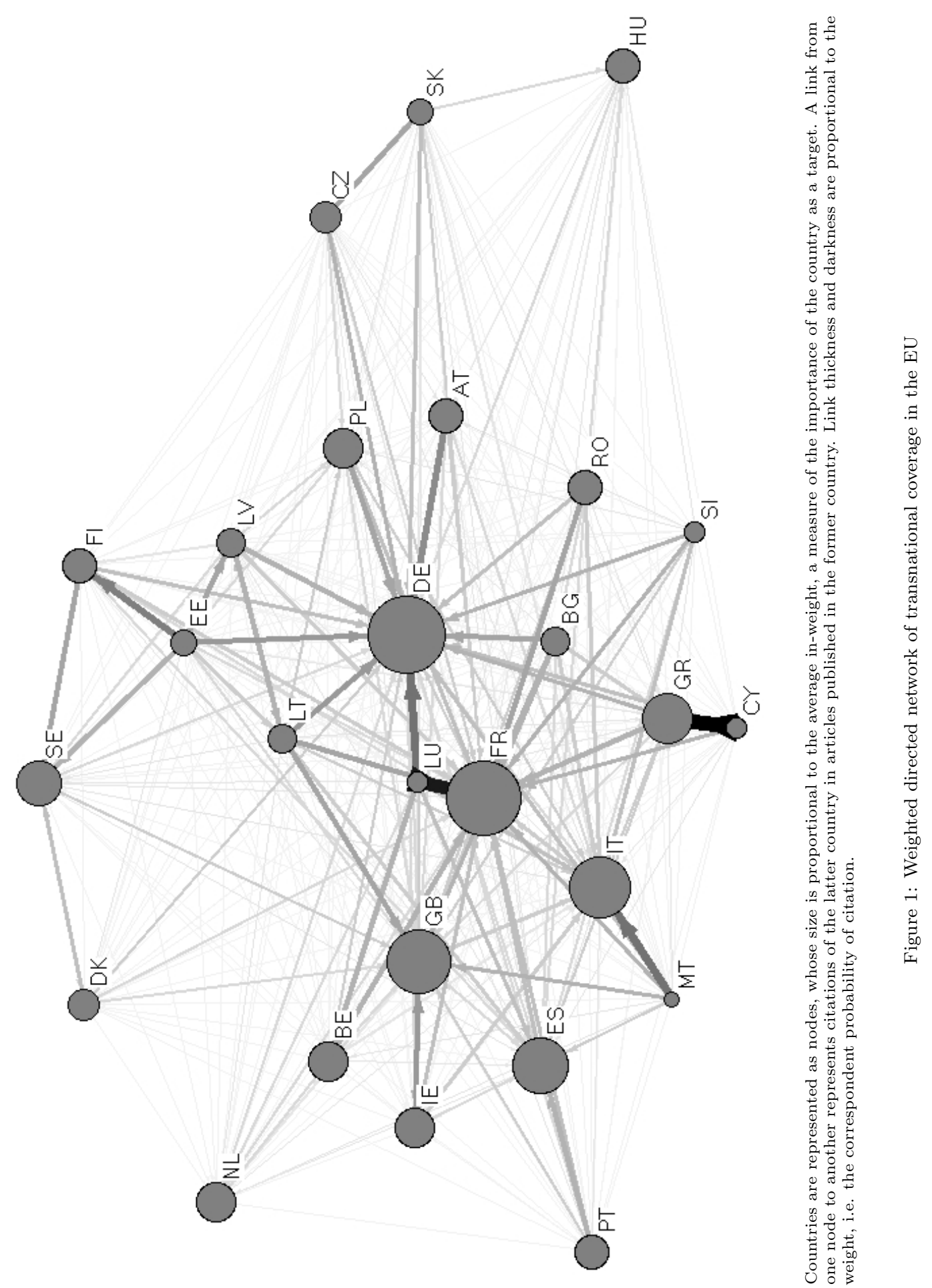
First, EU countries differ in their being the target of others' citations as shown by the size of the node, proportional to their average in-weight. The average inweight ranges from 0.00202 for Malta to 0.05042 for Germany. Among the most covered countries, Germany is followed by France (0.04965), the UK (0.03414), Italy (0.03270), and Spain (0.02759). Thus, countries differ greatly in their attraction of news, a feature that could be defined as "gravitational pull", for reasons that will be clearer in the next section. Node size is proportional to the average in-weight: intuitively, countries' population is a likely determinant of foreign citations as large countries tend to be ceteris paribus in the news relatively more than small countries do. However, other factors contribute to make a country an interesting target of foreign media (we shall investigate the relative impact of these factors in the following sections).

Second, in the graph the UK is much closer to continental Europe than in the real planisphere, meaning that the continental media pay attention to what happens in the UK and vice versa. On the other hand, Scandinavian countries and the Central and Eastern states occupy a relatively marginal role in the continental press.

Third, EU countries differ in terms of the total number of citations to EU partners and this appears to be negatively associated with country size: the largest countries exhibit a high presence in foreign EU press, but a rather low propensity to cite other countries. The average of the weights attached to outgoing links (average out-weight), a measure of the country's coverage of the other EU countries, ranges from 0.00772 for Italy to 0.02634 for Luxembourg. Among the least covering countries, Italy $(0.00772)$ is followed by the Netherlands (0.00859), Germany (0.00915), France (0.00930), and Spain (0.00944). This notwithstanding, the variance across countries in the level of coverage of other states is rather limited, suggesting that the imbalances between countries as targets of transnational media coverage are larger than those for countries as "producers" of transnational news. ${ }^{7}$

Fourth, while some countries concentrate their foreign citations to only a few partners (e.g. Cyprus toward Greece, Luxembourg toward France and Germany, Ireland toward the UK), others exhibit more uniformly distributed citations (e.g. Latvia, Hungary and Slovenia).

This heterogeneity is certainly not unexpected: the interest shown by the national media for news regarding EU partners depends not only on bilateralspecific factors (such as common language, history, etc.), but also on source country- and target country-specific determinants. The very same fact that the network is far from symmetric - as documented by the relatively low reciprocity (0.43 on a 0 to 1 scale, see the Appendix) - despite the relevance of symmetric determinants, such as geographical distance, suggests that country-specific factors play an important role in shaping the network. All this indicates that various factors may lie behind the actual structure of the network: the next section will

\footnotetext{
${ }^{7}$ Average in-weights dispersion is greater than average out-weights dispersion: the coefficient of variation in the former (latter) is $0.864(0.346)$.
} 
be devoted to illustrating the hypotheses to test and the empirical approach.

\section{Methodology}

\subsection{Hypotheses}

Previous quantitative works on foreign news coverage (e.g. Wu, 2000; Brüggemann and Kleinen-von Königslöw, 2009) indicate that the "eliteness" of a country (population size and level of economic development, here measured by the Gross Domestic Product (GDP) per capita in PPP) is associated positively with the probability of being covered by foreign media and negatively with the probability of covering foreign news. This represents the first hypothesis (H1) we test. The literature also indicates that physical and linguistic distance reduces foreign news, and this hypothesis (H2) will also be tested in our sample.

The existence of a euro-related dimension of transnational news coverage will be then analysed: the hypothesis to test is that foreign news coverage among members of the EZ is relatively more intense (H3). The economic literature on the impact of the euro on other variables has revealed the risk of spurious correlations: if the countries participating in the EZ are those naturally more interconnected, one could attribute to the EZ membership what is in fact the effect on foreign coverage of particularly strong trade ties. For this reason we test the relevance of a variable capturing historical trade links (H4) and check whether this addition changes our findings about the hypothesis H3.

Subsequently, borrowing on news value theory, we test whether events connected with the idea of "conflict" are news factors. In particular, we test whether Ireland and Greece were particularly covered because of their financial and economic conditions, as well as their resort to EU and intergovernmental loans (H5). Admittedly, Ireland and Greece are not the only countries experiencing some financial distress in the second half of 2010. To capture the intensity of such pressure we employ the long-term interest rates, which reflect the perceived country risk: the hypothesis is that the higher the sovereign bond yields (and the spreads vis-a-vis the German bunds), the larger the transnational media coverage of the countries in trouble. This is an alternative version of H5, say H5-bis.

It is known that international political meetings tend to attract media coverage: this is relevant in our study as the larger countries in the EZ may have received greater coverage because of their participation in G8 meetings (one was held in Canada in June 2010). Moreover, an important meeting between the French President Sarkozy and the German Chancellor Merkel took place in Deauville in October 2010: the two leaders released a joint Declaration about their engagement for a revision of the EU treaty as a way out of the crisis. We test whether a "meeting" effect can be detected in our sample (H6).

To check the robustness of the previous result, it is important to consider the fact that also historical and cultural linkages, not just the economic ones, can strengthen foreign coverage. Accordingly, we test whether bilateral news coverage is positively affected by the existence of historical ties (H7), and we focus on 
Comecon countries, Baltic countries, Ireland and the UK, Czech Republic and Slovakia.

Finally, we posit that there might be a relationship between a country's political position and the national media's attitude towards foreign news. Thus, we investigate whether the left-right ideological position of the parties in power in each country has an impact on the bilateral news coverage (H8). As long as journal articles cover national political speeches and party positions, a systematic relationship between the parties' ideological position and foreign coverage could emerge, in line with the idea that national actors contribute to shape the conflict constellation and thus influence news value (Adam, 2007). Finally, the impact of the ideological position of the parties in power about European integration will be assessed (H9).

\subsection{The gravity model of news}

The very fact that previous studies indicate that economic and population mass, as well as distance, impact on the bilateral news coverage suggest investigating the determinants of the strength on bilateral citations by estimating a specification that closely resembles a gravity model of trade (e.g. Rose, 2000; Baldwin and Taglioni, 2007; Disdier and Head, 2008; Head and Mayer, 2014). ${ }^{8}$ This allows to control for several factors at the same time, thereby overcoming the statistical limitations of those analyses that account for one variable at a time. As we shall show, this is particularly important for the main hypothesis we test (H3), that is that the participation of the source and destination countries in the EZ is conducive to higher than otherwise citations.

The baseline specification of the gravity model of news can be written as follows:

$$
\begin{aligned}
\operatorname{logit}\left(p_{i j}\right) & =\beta_{0}+\beta_{1} \log P_{o p_{i}}+\beta_{2} \log \text { Pop }_{j}+\beta_{3} \log G D P P C_{i}+ \\
& +\beta_{4} \log G D P P C_{j}+\beta_{5} \log \text { Dist }_{i j}+\beta_{6} \operatorname{Lan}_{i j}+\gamma Z+\epsilon_{i j}
\end{aligned}
$$

where the logit of $p_{i j}$ (see Section 2) is regressed on: a constant; the log of the average population (Pop) of the source $(i)$ and target $(j)$ country; the logs of the average GDPs per capita in PPP $(G D P P C)$ of the source and target country; the log of the weighted geographical distance between the two countries (Dist) $;{ }^{9}$ a dummy equal to one if the two countries share a common official

${ }^{8}$ The basic version of the gravity model of trade can be written as follows:

$$
\log X_{i j}=\alpha_{0}+\alpha_{1} \log G D P_{i}+\alpha_{2} \log G D P_{j}+\alpha_{3} \log D i s t_{i j}+\epsilon_{i j}
$$

where the $(\log )$ exports from country $i$ to country $j\left(X_{i j}\right)$ are a log-linear function of the countries' GDP and the geographical distance $\left(\right.$ Dist $\left._{i j}\right)$, plus a constant $\left(\alpha_{0}\right)$ and an error term $\left(\epsilon_{i j}\right) . \alpha_{1}$ and $\alpha_{2}$ measure the elasticity of trade to the GDP of the source and destination country. $\alpha_{3}$ measures the elasticity of trade to distance.

${ }^{9}$ We use the weighted distances (distwces) from the CEPII database (www.cepii.com): distances calculated using city-level data to account for the geographic distribution of population inside each nation in 2004 (see Mayer and Zignago, 2006, for details). Results do not significantly change with the other measures of distance in the dataset, nor do they change by using a dummy to identify neighbouring countries. 
language and zero otherwise (Lan). ${ }^{10} \mathrm{As}$ in $\mathrm{Wu}(2000)$ and Brüggemann and Kleinen-von Königslöw (2009), these variables allow to test H1 and H2: $\beta_{1}$ and $\beta_{3}$ are expected to be negative, $\beta_{2}$ and $\beta_{4}$ are expected to be positive (H1), and $\beta_{5}$ negative and $\beta_{6}$ positive (H2). To this specification, we add other variables to test the remaining hypotheses and to check the robustness of previous findings: $Z$ is a vector of additional variables that are added to test the remaining hypotheses.

The first variable we introduce is a dummy variable equal to one if both countries are in the EZ and zero otherwise (euro). This is added with a view to answering the main empirical question of this work: is there evidence of a euro-related dimension in the transnational coverage by the national media within the EU? This amounts to asking whether the coefficient of the dummy variable euro is statistically greater than zero. We shall then tackle alternative specifications to refine the analysis. ${ }^{11}$

\section{Results}

The estimation of the baseline specification (Model I in Table 1) yields results consistent with the literature and with the prima facie evidence provided by the visual inspection of the network in Section 3. The larger and more developed a country, the more likely it is cited by media in other countries and the less likely it is to cite other countries. ${ }^{12}$ In sum, the hypothesis $\mathrm{H} 1$ is not rejected by the data.

A second result is that the less distant the countries, the higher the probability of a citation. Similarly, sharing the same official language increases this

\footnotetext{
${ }^{10}$ When $\beta_{1}=\beta_{3}$ and $\beta_{2}=\beta_{4}$, Equation (2) simplifies to

$$
\operatorname{logit}\left(p_{i j}\right)=\beta_{0}+\beta_{1} \log G D P_{i}+\beta_{2} \log G D P_{j}+\beta_{5} \log D i s t_{i j}+\beta_{6} \operatorname{Lan}_{i j}+\gamma Z+\epsilon_{i j}
$$
}

which closely resembles Equation (1). Moreover, some specifications of the gravity model include GDP per capita in addition to GDP, although this functional form does not emerge from any well-known theoretical model of international trade (Disdier and Head, 2008).

${ }^{11}$ All the coefficients in (2) can be consistently estimated via OLS. However, since some of the regressors are at the country level and the errors are likely to be correlated within country, the usual OLS standard errors might greatly underestimate the true variance (Moulton, 1990). We therefore compute standard errors clustered at the source country level and report them in Table 1. Unfortunately, this decreases the test power. Therefore, we discuss also the test statistics calculated using the usual OLS standard errors, which are almost always smaller than the cluster-robust ones.

${ }^{12}$ To appreciate the parallel with the gravity model of trade, note that our dependent variable is (a monotonic transformation of) the fraction of articles in $i$ citing $j$ over all the articles produced in $i$. In a trade model, something similar is obtained by rearranging Equation (1) as follows:

$$
\log \frac{X_{i j}}{G D P_{i}}=\beta_{0}+\left(\beta_{1}-1\right) \log G D P_{i}+\beta_{2} \log G D P_{j}+\beta_{3} \log D i s t_{i j}+\epsilon_{i j}
$$

where the dependent variable is now the fraction of goods exported in $j$ on the total goods produced in $i$. When the elasticity of trade to GDP is less than one, the coefficient attached to the GDP of the source country in Equation (3) turns out to be negative. 
probability. This is evidence in favour of hypothesis $\mathrm{H} 2 .{ }^{13}$

The likelihood that EZ members cite other EZ members simply qua users of the same currency are, ceteris paribus, higher than otherwise. If the media of EZ members offer a relatively higher transnational coverage of news about other EZ members, we do not reject hypothesis $\mathrm{H} 3$, that is that there is a euro-related dimension in the transnational media coverage.

The euro dummy, however, could pick up the effect of other omitted variables, related to the participation in the EZ and to foreign coverage. For instance, if countries adopting the euro are those historically more integrated from a trade viewpoint, the dummy euro could simply proxy for historical preferential ties. To explore this hypothesis, we introduce in the estimation an additional regressor: the gross bilateral trade (export plus import) between countries $i$ and $j$ over total trade flows of country $i$. To limit the problems connected with the endogeneity of trade and monetary integration and to emphasize the historical traits of cross-country trade relationships, the variable is calculated as an average over the years 1999-2000. ${ }^{14}$ The new estimates (Model II) suggest that the inclusion of this variable is appropriate as it reduces the risk of attributing the effects of historically strong trade relationships to the participation in the EZ. All the explanatory variables but euro are statistically significant at the $1 \%$ significance level. On the contrary, euro has a lower coefficient (0.0884), which is statistically greater than zero only at the $10 \%$ level (one-sided $p$-value $=0.080) .{ }^{15}$

These findings, in line with the results in Wu (2000), suggest that $\mathrm{H} 4$ cannot be rejected and that previous conclusions on $\mathrm{H} 1$ and $\mathrm{H} 2$ are robust to the introduction of historical trade links among the explanatory variables. The impact of EZ membership on news coverage is positive and slightly significant, and H3 is not rejected. These results should be treated with care. First, we do not interpret these partial correlations in terms of causality. Second, we need to proceed further with the analysis to check whether these findings are robust to further changes in the estimated specification.

As anticipated, we test hypothesis $\mathrm{H} 5$ by including two dummies to account for the peculiar financial events in Greece and Ireland in 2010 (Model III). Besides testing $\mathrm{H} 5$, this represents a robustness check on previous results on H3: it is possible that the extraordinary exposure of these two countries to the attention of other EU members due to their financial problems drives the results about the significance of the euro variable in the previous specifications. Indeed, the estimate of the effect of euro in Model III further decreases (0.054) and

\footnotetext{
${ }^{13}$ Results are similar with the alternative measure of linguistic affinity from CEPII, i.e. a dummy equal to one if a language is spoken by at least $9 \%$ of the population in both countries.

${ }^{14} \mathrm{Had}$ we been using 2010 trade data, we would not have accounted for the effect of the currency union on the transnational coverage produced by the increased trade integration generated by the currency union itself.

${ }^{15}$ It is worth noting that the introduction of the new explanatory variable also affects the point estimates of all the other coefficients. This is not surprising given the fact that the GDPs of any pair of countries, as well as their geographical distance, are strongly correlated with the size of bilateral trade flows. It follows that the trade variable subsumes part of the effects of these variables.
} 


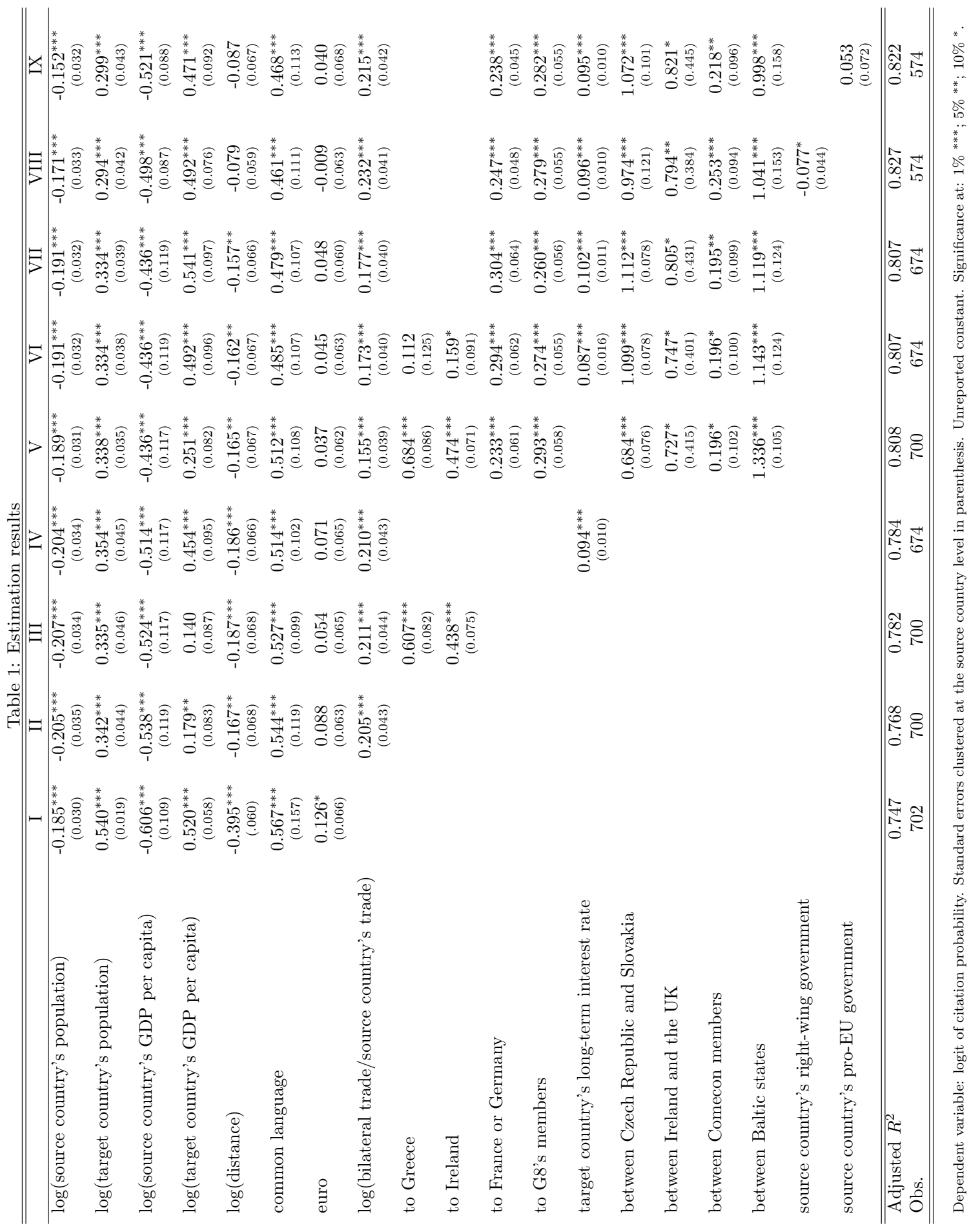


becomes not statistically greater than zero at the $10 \%{ }^{16}$

The hypothesis H5bis, a more general version of $\mathrm{H} 5$, can be tested via a more general approach to account for the different extent to which EU countries were exposed to the sovereign debt crisis (Model IV). We use a specification that, instead of the dummies for Greece and Ireland, includes a continuous variable with the average value of the long-term interest rates (percentage points) in the target country during the period of observation (August-November 2010). ${ }^{17}$ The estimated coefficient of this variable is positive and statistically significant: the higher the sovereign bond yields, the larger the transnational media coverage within the EU. Once the eruption of the sovereign debt crisis is taken into account, the data does not seem to provide empirical support to the hypothesis H3 that EZ membership strengthens news coverage (the parameter of euro is not statistically greater than zero at the $10 \%$ level) ${ }^{18}$

We now consider a hypothesis suggested by news value theory: larger countries in the EZ may receive greater coverage because of their participation in G8 meetings and other formal and informal international fora. In particular, a very important meeting that received great media coverage took place in Deauville in October 2010 between the French President Sarkozy and the German Chancellor Merkel. Model V in Table 1 reports the estimates of a specification like Model III, but including a dummy that takes the value of one if the target countries belong to the G8, and a dummy equal to one when Germany and France are the target countries. The estimated coefficients of these variables are positive and significant, so that $\mathrm{H} 6$ is not rejected by the data. ${ }^{19}$ Moreover, we include a set of dummies for those pairs of countries that are integrated for historical (non-euro-related) reasons: a dummy equal to one if the two countries are Baltic states and zero otherwise; a dummy equal to one if the two countries belonged to the Comecon; a dummy taking the value of one if the two countries are the Czech Republic and Slovakia; a dummy equal to one if the two countries are Ireland and the UK. ${ }^{20}$ All these dummies appear positive, as expected, and statistically significant, providing evidence in favour of the hypothesis H7. The estimate of the coefficient of euro decreases further (0.037) and is not statistically greater than zero (one-sided $p$-value $=0.210$ using the usual OLS standard error).

To check the robustness of these findings, in Model VI we add the long-term interest rate of the target country to Model V. The dummies identifying the coverage of Greece and Ireland lose their significance, while all the remaining variables keep their sign, size and significance. This is in line with the idea

\footnotetext{
${ }^{16}$ The coefficient is not statistically greater than zero at the $10 \%$ level even using the usual OLS standard errors (one-sided $p$-value: 0.129 ).

${ }^{17}$ Due to the lack of comparable data for Estonia, the sample contains only 674 observations.

${ }^{18}$ We also estimated quantile regressions to look for significant effects of the euro on some conditional quantile of $\operatorname{logit}\left(p_{i j}\right)$. All the conditional quantiles were not statistically different from the conditional mean and the euro dummy was never statistically significant.

${ }^{19}$ Given that the GDP per capita and population are included in the specification, the G8 dummy variable is not capturing economic size, but an effect that adds to it.

${ }^{20}$ We also included a dummy for any pair among Belgium, the Netherlands and Luxembourg, but it was not statistically significant and was thus omitted.
} 
that it was the financial turmoil that made these (and a few other) countries particularly newsworthy. ${ }^{21}$ Model VII shows the results when the long-term interest rate is included and the previous dummies are excluded. As before, the participation of the source and target countries in the EZ does not appear associated with higher odds of citation (once again the coefficient of euro is not statistically greater than zero at the $10 \%$ level, even using the usual OLS s.e., one-sided $p$-value $=0.144$ ).

Finally, in Models VIII and IX we explore the relationship between a country's political position and the national media's attitude towards foreign news. To do so we use the 2010 Chapel Hill expert surveys dataset, including estimates of party positioning on European integration and ideology issues for national parties in various European countries (Bakker et al., 2012). We calculate the position of the parties in power in each state by taking the simple average of all the party position values attributed to the parties forming government coalitions in late 2010. In Model VIII, we look at the general left-right ideological position starting from the experts' attribution of values on a 0 (extreme left) to 10 (extreme right) scale. The estimated coefficient is negative and statistically significant at the $10 \%$ level, thus suggesting that in conservative countries the media tend to be less interested in covering foreign news, in line with H8. In Model IX, we look at the ideological position of the parties in power about European Integration, starting from the experts' attribution of values on a 1 (strongly oppose) to 7 (strongly in favour) scale. We find a positive but not statistically significant coefficient, which indicates that there does not seem to be evidence in favour of H9.

\section{Conclusions}

Exploiting a new dataset on the transnational coverage by 148 EU national newspapers of stories related to other EU member states, this paper analyses the coverage network in the EU. The analysis uncovers a large cross-country heterogeneity both in the source and target countries. The representation of the network of bilateral transnational media coverage in the EU allows us to make a preliminary visual assessment and draw some clues about the determinants of such heterogeneity. Geographical distance, among the bilateral factors, and country size, among the country-specific factors, appear as likely sources of the observed variation. On this basis and taking stock of previous studies on both foreign news coverage and news value theory, we identify nine systemic factors that might exert influence on international news coverage and derive nine hypotheses regarding the bilateral cross-country media coverage in the EU. The econometric analysis, which builds on the gravity model of trade, provides

\footnotetext{
${ }^{21}$ The dummy "to Ireland" remains significant at the $10 \%$ only because standard errors are clustered at the source country level, and the variable is constant at the target country level. If we cluster standard errors at the level of the target country, the dummy loses its significance (s.e. $=0.231, p$-value $=0.489)$.
} 
more precise findings on the determinants of foreign coverage and more robust evidence on the nine hypotheses (H1 to H9) we test.

From the analysis some evidence emerges in favour of the existence of a gravity model of news, where country size and economic development of the target (source) country are positively (negatively) associated with the odds of observing news regarding the target country in the media of the source country (H1 and H2). Moreover, historical, linguistic and economic ties (this latter proxied by the relative strength of bilateral trade linkages) increase the odds of transnational coverage ( $\mathrm{H} 4$ and $\mathrm{H} 7)$. The political attitude of the incumbent governments is also significantly related to the odds of foreign citations (H8), and being conservative is associated with lower transnational coverage.

Moreover, in line with news value theory, we find that countries participating in international meetings (i.e., G8 and Deauville in 2010) attract the attention of foreign media, as also do those countries which are involved in events associated with the idea of "conflict" (i.e., the sovereign debt turmoil in 2010) (H5 and H5bis).

As to the main hypothesis in this study (i.e. H3), we do not find robust evidence that the media in EZ member states show relatively greater interest for what happens in other EZ partners than for what occurs in EU members not participating in the EZ. Indeed, some prima facie evidence suggesting relatively stronger links among EZ countries is not robust across the various specifications. In fact, once the historical levels of trade integration and the country-contingent positions in the recent sovereign debt crisis are accounted for, the null hypothesis of no systematic difference in coverage probabilities between EZ members and the other EU countries cannot be rejected. From a methodological viewpoint, this warns against adopting parsimonious specifications in the estimation of the systemic determinants of foreign news coverage, as done in previous works.

We do not venture into either the debate about the impact of the media on European integration (see European Commission (2006) and Trenz (2008) among others) nor into the vexed questions regarding the relationship between the media and the creation of a European public sphere (see Peters et al. (2005), Sifft et al. (2007), Pfetsch (2008), and Koopmans and Statham (2010) for qualitative and quantitative analyses of the issue, and Meyer (2010) for an historical perspective) nor on the alleged communication deficit in the EU (Meyer, 1999). However, our findings seem to suggest that non-economic integration among the EU countries sharing the same currency is not relatively stronger than that among the other EU states. Deeper economic integration does not seem to strengthen per se the newsworthiness of events occurring in other countries within the EZ and the horizontal Europeanization of the national media spheres.

Nonetheless, we suggest using great care in the interpretation of these results. To the extent that trade and monetary integration processes are affected by common determinants, our findings could be interpreted as signalling the lack of an impact on transnational media coverage arising from the participation of countries in the EZ in addition to that already implied by the relatively higher level of economic integration characterizing the EZ member states. Similarly, while it is true that Greece and Ireland did receive extraordinary coverage 
mainly because at the centre of the turmoil in the sovereign debt markets, it is their participation in the EZ that made the discussions about their bail-out so politically tense and the spillovers of the situation so far reaching. These observations suggest that the understanding of the "ordinary", so to speak, determinants of EU bilateral transnational coverage would benefit from repeating the analysis when the economic and financial tensions in the EZ will ease.

Finally, it is worth stressing that although the analysis falls exclusively on the horizontal dimension of the Europeanization of the national media spheres, we do not suggest that an "Europeanization aloof from the EU", to use Brüggemann and Kleinen-von Königslöw's (2009) words, is the only pattern of Europeanization at work (and worth investigating). In this work we do not "measure" and compare the various patterns of Europeanization of national media spheres, as done in Sifft et al. (2007) and Brüggemann and Kleinen-von Königslöw (2009), for two main reasons: first, we did not monitor national media's references to the EU and the EZ; second, the gravity model of news is appropriate to cover only bilateral coverage. It is well possible that the introduction of the euro did not promote grater media coverage of foreign news among the EZ member states, but at the same time it increased the vertical dimension of the Europeanization of the national media spheres, for instance through greater coverage of EU and EZ institutions and bodies (e.g., the ECB and the Eurogroup) by the national media. The investigation of this issue will be the object of future research.

\section{Acknowledgements}

The authors gratefully acknowledge Tommaso Grassi and Economisti Associati for the data. They also thank Giacomo Degli Antoni, Andrej Mrvar, Simona Piattoni, Carlo Ruzza, Stefano Schiavo and two anonymous referees for useful suggestions and comments. Usual caveats apply.

\section{References}

Adam, S. (2007). Domestic adaptations of Europe: A comparative study of the debates on EU enlargement and a common constitution in the German and French quality press. International Journal of Public Opinion Research 19(4), 409-433.

Bakker, R., C. De Vries, E. Edwards, L. Hooghe, S. Jolly, G. Marks, J. Polk, J. Rovny, M. Steenbergen, and M. A. Vachudova (2012). Measuring party positions in Europe: The Chapel Hill expert survey trend file, 1999-2010. Party Politics, forthcoming.

Baldwin, R. and D. Taglioni (2007). Trade effects of the Euro: A comparison of estimators. Journal of Economic Integration 22(4), 780-818.

Barthélemy, M., A. Barrat, R. Pastor-Satorras, and A. Vespignani (2005). Characterization and modeling of complex weighted networks. Physica A 346, $34-43$. 
Boccaletti, S., V. Latora, Y. Moreno, M. Chavez, and D.-U. Hwang (2006). Complex networks: Structure and dynamics. Physics Reports 424(4-5), 175308.

Bonatti, L. and A. Fracasso (2013). The German model and the European crisis. JCMS: Journal of Common Market Studies 51(6), 1023-1039.

Brettschneider, F., M. Maier, and J. Maier (2003). From D-Mark to Euro: the impact of mass media on public opinion in Germany. German Politics 12(2), $45-64$.

Brüggemann, M. and K. Kleinen-von Königslöw (2009). "Let's talk about Europe": Why Europeanization shows a different face in different newspapers. European Journal of Communication 24(1), 27-48.

Brüggemann, M. and K. Kleinen-von Königslöw (2013). Explaining cosmopolitan coverage. European Journal of Communication 28(4), 361-378.

De Nooy, W., A. Mrvar, and V. Batagelj (2011). Exploratory Social Network Analysis with Pajek. Cambridge: Cambridge University Press.

De Vreese, C. H. (2001). "Europe" in the news: A cross-national comparative study of the news coverage of key EU events. European Union Politics 2(3), $283-307$.

Disdier, A.-C. and K. Head (2008). The puzzling persistence of the distance effect on bilateral trade. The Review of Economics and Statistics 90(1), 37-48.

Economisti Associati (2011). Feasibility study for the preparatory action "ERASMUS for journalists" - Statistical review. Specific Contract 30-CE-0343284/0024, European Commission. http://ec.europa.eu/digital-agenda/en/europeanjournalism-study.

European Commission (2006). White paper on a European communication policy. $\operatorname{COM}(2006) 35$.

Fagiolo, G. (2007). Clustering in complex directed networks. Physical Review E 76, 026107.

Firmstone, J. (2008a). Approaches of the transnational press to reporting Europe. Journalism 9(4), 423-442.

Firmstone, J. (2008b). The editorial production process and editorial values as influences on the opinions of the British press towards Europe. Journalism Pratice 2(2), 2012-229.

Frankel, J. A. and A. K. Rose (1998). The endogeneity of the optimum currency area criteria. The Economic Journal 108(449), 1009-1025. 
Galtung, J. and M. H. Ruge (1965). The structure of foreign news: The presentation of the Congo, Cuba and Cyprus crises in four Norwegian newspapers. Journal of Peace Research 2(1), 64-90.

Head, K. and T. Mayer (2014). Gravity equations: Toolkit, cookbook, workhorse. In G. Gopinath, E. Helpman, and K. Rogoff (Eds.), Handbook of International Economics, Volume 4. Amsterdam: Elsevier.

Koopmans, R. and J. Erbe (2004). Towards a European public sphere? Innovation: The European Journal of Social Science Research 17(2), 97-118.

Koopmans, R. and P. Statham (2010). The Making of a European Public Sphere: Media Discourse and Political Contention. Cambridge: Cambridge University Press.

Mayer, T. and S. Zignago (2006). Notes on CEPII's distances measures. www . cepii.com/distance/noticedist_en.pdf.

Meyer, C. (1999). Political legitimacy and the invisibility of politics: Exploring the European Union's communication deficit. JCMS: Journal of Common Market Studies 37(4), 617-639.

Meyer, J.-H. (2010). The European Public Sphere: Media and Transnational Communication in European Integration, 1969-1991. Stuttgart: Franz Steiner Verlag.

Moulton, B. R. (1990). An illustration of a pitfall in estimating the effects of aggregate variables on micro units. The Review of Economics and Statistics 72(2), 334-338.

Newman, M. E. J., S. Forrest, and J. Balthrop (2002). Email networks and the spread of computer viruses. Physical Review E 66(3), 035101.

Peters, B., S. Sifft, A. Wimmel, M. Brüggemann, and K. Kleinen-von Königslöw (2005). National and transnational public spheres: the case of the EU. European review 13(5), 139-160.

Pfetsch, B. (2008). Agents of transnational debate across Europe. the press in emerging European public sphere. Javnost 15(4), 21-40.

Rose, A. K. (2000). One money, one market: Estimating the effect of common currencies on trade. Economic Policy: A European Forum 30, 7-33.

Sander, H. and S. Kleimeier (2004). Convergence in euro-zone retail banking? what interest rate pass-through tells us about monetary policy transmission, competition and integration. Journal of International Money and Finance 23(3), 461-492. 
Sifft, S., M. Brüggemann, K. Kleinen-von Königslöw, B. Peters, and A. Wimmel (2007). Segmented Europeanization: Exploring the legitimacy of the European Union from a public discourse perspective. JCMS: Journal of Common Market Studies 45(1), 127-155.

Statham, P. (2008). Making Europe news: How journalists view their role and media performance. Journalism 9(4), 398-422.

Statham, P. and R. Koopmans (2009). Political party contestation over Europe in the mass media: who criticizes Europe, how, and why? European Political Science Review 1, 435-463.

Trenz, H.-J. (2008). Understanding media impact on European integration: Enhancing or restricting the scope of legitimacy of the EU? Journal of European Integration 30 (2), 291-309.

Werder, O. (2002). Debating the euro media agenda-setting in a cross-national environment. International Communication Gazette 64(3), 219-233.

$\mathrm{Wu}, \mathrm{H}$. (2000). Systemic determinants of international news coverage: a comparison of 38 countries. Journal of Communication 50(2), 110-130. 
Table 2: Summary statistics

\begin{tabular}{lcccclclr}
\hline \hline & Mean & Std. Dev. & Median & Min & & Max & Obs \\
\hline weights & 0.0150 & 0.0183 & 0.0086 & 0.0004 & (NL,MT) & 0.1823 & (CY,GR) & 702 \\
in-strengths & 0.3910 & 0.3376 & 0.2626 & 0.0526 & (MT) & 1.3110 & (DE) & 27 \\
out-strengths & 0.3940 & 0.1352 & 0.3624 & 0.2008 & (IT) & 0.6849 & (LU) & 27 \\
outward disparity & 0.0863 & 0.0235 & 0.0820 & 0.0628 & (LV) & 0.1803 & (CY) & 27 \\
inward disparity & 0.0779 & 0.0456 & 0.0565 & 0.0439 & (DE) & 0.2049 & (LV) & 27 \\
clustering coefficient & 0.0589 & 0.0128 & 0.0541 & 0.0428 & (CY) & 0.0909 & (DE) & 27 \\
\hline \hline
\end{tabular}

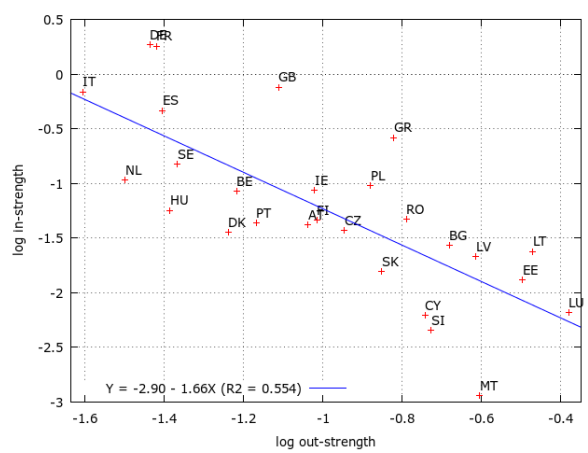

(a) log in-strength vs. log out-strength

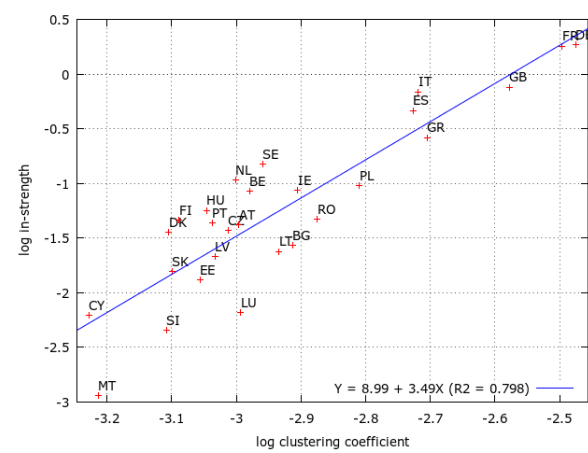

(b) log in-strength vs. log clustering coefficient

Figure 2: Scatter plots (with least squares fit)

\section{A. Exploratory weighted network analysis}

The EU transnational coverage network, plotted in Figure 1, is fully described by the $27 \times 27$ weights matrix $\mathbf{W}=\left\{p_{i j}\right\}$, with $p_{i i}=0$. The network is complete. The $702(27 \times 26)$ weights $p_{i j}$ are approximately log-normally distributed. The summary statistics are reported in Table 2 . The maximum (minimum) is 0.18225 $(0.00043)$ and it corresponds to the probability of Greece (Malta) appearing in articles published in Cyprus (the Netherlands).

Table 2 reports the summary statistics of common network measures: instrengths and out-strengths, ${ }^{22}$ inward and outward node disparities, and clustering coefficients (see Barthélemy et al., 2005; Boccaletti et al., 2006).

As shown by Figure 2(a), there is a clear negative linear correlation between log out-strengths and log in-strengths: the more important a country is as a target, the lower its propensity to cite other countries.

The degree of heterogeneity in foreign citations for each country can be assessed by looking at node disparity. Since the network is directed, both inward and outward disparities are computed. Node outward disparity is the Herfindahl-

\footnotetext{
${ }^{22}$ The in-strength of node $i$ is the sum of the weights of the links directed toward $i$ : $s_{i}=\sum_{j} p_{i j}$. As such, the in-strength is proportional to the average in-weight. In a similar manner, the out-strength, i.e. the sum of the weights attached to outgoing links, is proportional to the average out-weight.
} 
Hirschman index of the weights attached to outgoing links. ${ }^{23}$ The average outward disparity in the network is 0.0863 (Table 2). The highest disparities occur in Cyprus (0.1803), Luxembourg (0.111) and Italy (0.1054); the lowest in Latvia (0.0628), Hungary (0.0632) and Slovenia (0.0637).

Likewise, node inward disparity is the Herfindahl-Hirschman index of incoming link weights. The nodes characterized by the highest inward disparities are Latvia (0.2049), Estonia (0.1794) and Lithuania (0.1597). The lowest are Germany (0.0439), Spain (0.0442) and the Netherlands (0.0444).

As for the clustering coefficient, since the network is weighted and directed, we compute the clustering coefficient following Fagiolo (2007), who adapts to directed networks the index used in weighted undirected networks. ${ }^{24}$ The resulting average clustering in the normalized network is 0.0589 (Table 2), with a coefficient of variation of 0.217 . The highest clustering happen to be in Germany (0.0909), France (0.0890) and the UK (0.0820); the lowest in Cyprus (0.0428), Malta (0.04343) and Slovenia (0.0483). As shown by Figure 2(b), there is a clear positive linear correlation between (the logs of) clustering and in-strength.

Finally, we look at the degree of reciprocity, i.e. the tendency of node pairs to form mutual connections. We measure reciprocity by adapting a measure used in the literature for binary directed networks to the weighted case, i.e. the number of bi-directed arcs on the total number of arcs in the network (e.g. Newman et al., 2002). We compute the reciprocity index as follows:

$$
R=\frac{\sum_{i, j \neq i} \min \left(p_{i j}, p_{j i}\right)}{\sum_{i, j \neq i} p_{i j}}
$$

The index is bound between 0 (no reciprocity) and 1 (perfect reciprocity). In our network it is 0.43 .

\footnotetext{
${ }^{23}$ The outward disparity of node $i$ is $\sum_{j}\left(p_{i j} / s_{i}\right)^{2}$, where $s_{i}$ is the out-strength of $i$ (Boccaletti et al., 2006, p.199)

${ }^{24}$ We normalize the weights matrix, $\overline{\mathbf{W}}=\mathbf{W} / \max \left(\left\{p_{i j}\right\}\right)$, and compute the clustering coefficient of node $i$ as follows:
}

$$
C_{i}=\frac{\left[\left(\overline{\mathbf{W}}^{\left[\frac{1}{3}\right]}+\overline{\mathbf{W}}^{T\left[\frac{1}{3}\right]}\right)^{3}\right]_{i i}}{2\left(d_{i}^{t o t}\left(d_{i}^{t o t}-1\right)-2 d_{i}^{\leftrightarrow}\right)}
$$

where, at the numerator, $[\mathbf{X}]_{i i}$ stands for the $(i, i)$ element of a generic matrix $\mathbf{X}, \mathbf{X}^{\left[\frac{1}{3}\right]}$ for the cube root element-by-element of $\mathbf{X}, \mathbf{X}^{T}$ for the transpose of $\mathbf{X}$; at the denominator, $d_{i}^{\text {tot }}$ is the total degree of node $i$, i.e. the number of in-going and out-going links of $i$, and $d_{i}^{\leftrightarrow}$ is the number of bilateral links between $i$ and its neighbors (Fagiolo, 2007, p. 3). Since our network is complete, we have:

$$
2\left(d_{i}^{\text {tot }}\left(d_{i}^{\text {tot }}-1\right)-2 d_{i}^{\leftrightarrow}\right)=2(2(n-1)(2(n-1)-1)-2(n-1))=8(n-1)(n-2)
$$

where $n(=27)$ is the number of nodes. The normalization of $\mathbf{W}$ changes the value of the coefficients, but not the resulting order of the nodes in terms of clustering. 